\title{
Construction and Standardization of Achievement Test in Economics
}

\author{
Manu Sharma ${ }^{1}$, Dr. Gurmit Singh ${ }^{2}$ \\ ${ }^{1}$ Research Scholar, Panjab University, Chandigarh, Punjab, India \\ ${ }^{2}$ Assistant Professor, Malwa Central College of Education for Women, Ludhiana, Punjab, India
}

\begin{abstract}
The paper presents the details of the development and standardization of the test of achievement in Economics for IX class under Punjab School Education Board. The test initially consisted of 181 items. After discussion with experts items were reduced to 143. After item analysis the final draft was reduced to 58 items. The test-retest reliability was found to be 0.87 . Validity was established by content validity method.
\end{abstract}

Keywords: Construction, Standardization, Achievement test, Economics

\section{Introduction}

Teaching learning process without evaluation turns to a meaningless process hence good tools of evaluation are the prime requirement of any learning process. Achievement tests are one of the means of evaluation. The need was felt to construct an achievement test in economics assessing the achievement of the students in the subject at the secondary stage i.e. IX level, as there was lack of suitable achievement test in Economics among the existing tests. Good's Dictionary of Education (1959) defines Achievement as the knowledge attained or skills developed in school subject usually designated by the test scores or by marks assigned, by the teacher or by both whereas according to Webster Dictionary of Education (1989) Academic achievement is the performance by a student in a course based on formal study in an institution of learning. This test contains the content which students of IX class were expected to learn after their instructional programme at secondary level.

\section{Method of Construction of the Test}

This test was constructed on the basis of the objectives of teaching; knowledge, understanding and application, in Economics at the secondary stage. Keeping in view these objectives, the syllabus of economics portion was analyzed and thoroughly read from the economics text books of IX class prescribed by the Punjab School Education Board, used in the government school at secondary stage. Then the items were prepared from the content which students have learnt in their IX class. As Crow and Crow (1954) defined Achievement as the extent to which learner is profiting from instructions in a given area of learning.

Before constructing the achievement test, investigators started searching and going through the various tests available for testing in the field of economics. It was felt that lack of suitable test to evaluate achievement in economics. Various tests made by Punjab School Education Board were read, discussion with various social science teachers and assistant professors in social sciences in different colleges of education was done. Efforts were put to identify the important concepts of economics at IX level. On this basis preliminary draft of the test was prepared. Items are framed as multiple choice questions as there are superior to other types of tools of evaluation. According to Zeidner (1987) multiple choice questions help students to avoid losing points for poor spelling, grammar or poor handwriting ability while according to Dufresne, Leonard and Gerace (2002) ,It is an efficient way to collect and grade examination from large no. of test takers $^{\text {ee }}$. It enables instructors to ask a large number of questions on a wide range of subject materials (Becker \& Johnson, 1999; Walstad \& Robson, 1997; Lukhele, Thissen \& Wainer, 1994),

At the initial stage preliminary draft was prepared corresponding to three concepts of economics of IX class. This draft consists 181 items covering the major objectives of teaching; knowledge, understanding and application in economics at the secondary stage. Items having similar concepts were grouped at one place; Items were multiple types i.e. every item was fed with four options in which only one option was the appropriate answer. Here the students were expected to answer the questions by selected the right option from among the four listed responses. All the items were evaluated by the experts as well as by the investigator in order to remove vagueness, ambiguous terms and language difficulty in the format of test items. 30 items were deleted and few items were modified as per suggestions received from the experts. In this way preliminary draft with 151 items was made.

After finalizing the test items were administered on the 25 , IX Passed students of Moga (Preliminary try out). This attempt was made to check the difficulty level as well as any language problem occurring in the construction of the test. These all students were having difference in the achievement in economics. All the students were given separate answer sheet on which they were supposed to mark the right answer, after giving the required instructions about the test. There was no time limit and time taken by every student was noted down. Out of 151,8 items were found to be confusing/difficulty by the students. Thereby out of 151 items 8 items were removed from the draft consisting 143 items was prepared keeping in view the nature of content as well as difficulty level. 


\section{International Journal of Science and Research (IJSR) \\ ISSN (Online): 2319-7064}

Index Copernicus Value (2013): 6.14 | Impact Factor (2014): 5.611

Every concept along with number of items has been shown

in table I.

Table I: Concept-wise distribution of items included in the preliminary draft

\begin{tabular}{|l|c|}
\hline \multicolumn{1}{|c|}{ Name of the concepts of Economics } & Number of the items \\
\hline Basic Concepts & 53 \\
\hline Economy- An Introduction and Types & 47 \\
\hline An Overview of The Indian Economy & 43 \\
\hline Total & 143 \\
\hline
\end{tabular}

Distribution of items according to objectives wise is as under in table II

Table II: Objective wise distribution of items included in the preliminary draft

\begin{tabular}{|c|c|c|c|c|}
\hline Name of the concepts of Economics & Knowledge & Understanding & Application & Total \\
\hline Basic Concepts & 19 & 23 & 11 & 53 \\
\hline Economy- An Introduction and Types & 23 & 20 & 4 & 47 \\
\hline An Overview of The Indian Economy & 18 & 22 & 3 & 43 \\
\hline Total & 60 & 65 & 18 & 143 \\
\hline
\end{tabular}

Final tryout of the test: The test was administered to 121 students of IX class who had just passed IX class exams, for final tryout. The answer sheets were scored with the help of scoring key. Each correct answer was given the score of one and total scores obtained by the student was total number of correct answer.

\section{Item Analysis}

Difficulty value of the test items: The difficulty value of each of the item was calculated with the help of following formula:

$$
\text { The difficulty value of each item }=\frac{\text { No. of students responding correctly to the item }}{\text { Total number of students }}
$$

Discriminative value of the items: 121 Students for the final tryout were arranged in descending order of their performance. The student getting highest marks were ranked first; the student next higher marks were ranked second and so on. Thus the student getting lowest marks was ranked 121th. After arranging the students in descending order of their performance, they were classified into three groups (Kellyes dichotomy, 1939). The first group is termed as higher group consisting $27 \%$ of the top students which comes out to be 33 . The second consisted of next 55 students, which formed middle $46 \%$ of the total students. The third group termed as lower group which consisting of $27 \%$ of the total students on the lower side, it again consisting of 33 students. In order to find out the discriminative value of the various items, the two groups- higher and lower consisting of the top $27 \%$ of the students and bottom $27 \%$ of the students were compared. The discriminative value of the items was computed with the help of the following formula:

RH-RL

Discriminative value Total number of students in upper or lower group

Where,

$\mathrm{RH}=$ is the number of students responding correctly out of the higher group
$\mathrm{RL}=$ is the number of students responding correctly out of the lower group.

All those items were selected for the final test which have difficulty value as well as discriminating value of 0.20 0.80

In this way the total number of items selected for the final draft of the test was 58. These 58 items selected after the final tryout had to be placed in order of difficulty. In this way final form of Achievement Test in Economics comprised of 58 items. Finally, instructions were carefully reviewed and modifications were done wherever necessary. The time limit of the test was fixed on the basis of time taken by 90 percent of the students on the final tryout, which was 80 minutes, including 5 minutes for instructions. Every concept along with number of items has been shown in table III.

Table III: Concept-wise distribution of items included in the final draft

\begin{tabular}{|l|c|}
\hline \multicolumn{1}{|c|}{ Name of the concepts of Economics } & Number of the items \\
\hline Basic Concepts & 19 \\
\hline Economy- An Introduction and Types & 15 \\
\hline An Overview of The Indian Economy & 24 \\
\hline Total & 58 \\
\hline
\end{tabular}

Distribution of items according to objectives wise is as under in table IV

Table IV: Objective wise distribution of items included in the final draft

\begin{tabular}{|l|c|c|c|c|}
\hline $\begin{array}{c}\text { Name of the } \\
\text { concepts of } \\
\text { Economics }\end{array}$ & Knowledge & Understanding & Application & Total \\
\hline Basic Concepts & 7 & 6 & 6 & 19 \\
\hline $\begin{array}{l}\text { Economy- An } \\
\text { Introduction } \\
\text { and Types }\end{array}$ & 6 & 7 & 2 & 15 \\
\hline $\begin{array}{l}\text { An Overview } \\
\text { of The Indian } \\
\text { Economy }\end{array}$ & 12 & 10 & 2 & 24 \\
\hline Total & 25 & 23 & 10 & 58 \\
\hline
\end{tabular}

Reliability of the Test: Equivalent forms method and split half method is not applicable here as the achievement test 


\section{International Journal of Science and Research (IJSR) \\ ISSN (Online): 2319-7064}

Index Copernicus Value (2013): 6.14 | Impact Factor (2014): 5.611

in economics is heterogeneous and test items having been arranged content wise, the two halves could not been identical. Therefore, test retest method of reliability was found to be the most suitable for the Achievement Test in Economics. The reliability was found to be the most suitable for the Achievement Test in Economics. The reliability study of the achievement test was given after a week. The product moment coefficient of correlation between the two test scores was found to be 0.87 . The coefficient of correlation is fairly high, which proves the soundness of the test.

Validity of the Test: Validity means truthfulness. It refers to the degree to which it measures, what it intend to measure. Test validity also refers to the extent to which conclusions and decisions made based on test scores are appropriate and meaningful. Validity of a test must be established prior to use and in the accuracy of specific prediction made from its scores. The test was validated against the criteria of "content validity". The content validity is concerned with the logical adequacy of sampling of a specified universe of contents. To determine content validity the test items, the panel consisting of six experts in subject matter. The panel was asked to identify which test items corresponded to which outcome. The panel also completed the test so that scoring key could be verified. The experts agreed with the investigator on the assignment of the test items to objectives $90 \%$. This concurrence of percentage was taken as evidence of content validity.

\section{References}

[1] Becker, W.E., \& Johnston, C. (1999). The relationship between multiple choice and essay response questions in assessing economics understanding. Economic Record, 75(231), 348-357. Retrieved from onlinelibrary.wiley.com/ doi/10.1111/j.14754932.1999...x/abstract

[2] Crow, L.D. \& Crow, A. (1954). Human development and learning. Delhi: Ram Nagar Burasian Publishing House.

[3] Dufresne, R.J., Leonard, W.J., Gerace, W.J. (2002). Making sense of students ${ }^{\text {ee }}$ answers to multiple-choice questions. The Physics Teacher, 40,174-180.

[4] Good, C.V. (1959). Dictionary of Education. New York: McGraw Hill Book Company Inc.

[5] Kelley, T. L. (1939). The selection of upper and lower groups for the validation of test items. Journal of Educational Psychology, 30, 17-24.

[6] Lukhele, K., Thissen, D., \& Wainer, H. (1994). On the relative value of multiple-choice, constructed response, and examinee-selected items on two achievement tests. Journal of Economic Education, 31(3), 234-250. Retrieved from www.jstor.org/stable/1435268

[7] Walstad, W. B., \& Robson, D. (1997). Differential item functioning and male -female differences on multiple choice tests in economics. Journal of Economic Education, 28, 155-171. Retrieved from www.jstor.org/stable/1182910

[8] Webster's Dictionary of Education (1989). Spring Field, Massachusetto: $\mathrm{G}$ and $\mathrm{C}$ Merriain $\mathrm{Co}$ publishers.

[9] Zeidner, M. (1987). Essay versus multiple-choice type classroom exams: the student perspective. Journal of Educational Research, 80, 352-358. Retrieved from www.jstor.org/stable/27540265 